\title{
Pregnancy and Periodontitis: E-learning
}

\section{Periodontitis Knowledge Hub}

Are you aware of the fact that maintaining optimal oral health is crucial for the mother and the newborn?

Assess your knowledge on pregnancy and periodontitis with our e-learning module for healthcare practitioners, developed by a panel of experts to aid earlier diagnosis and better patient outcomes.

\section{Visit the knowledge hub to access e-learning modules:}

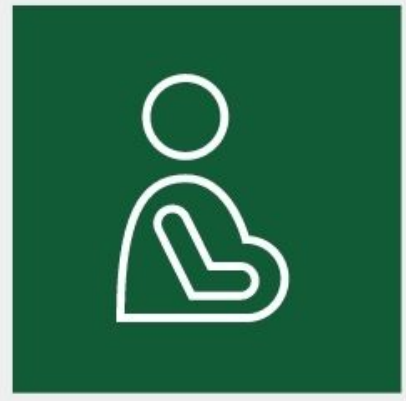

Pregnancy \& Periodontitis

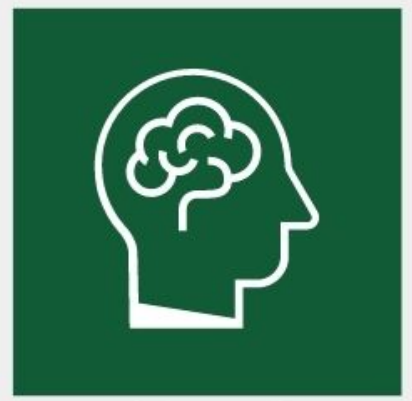

Cognitive Decline \& Periodontitis

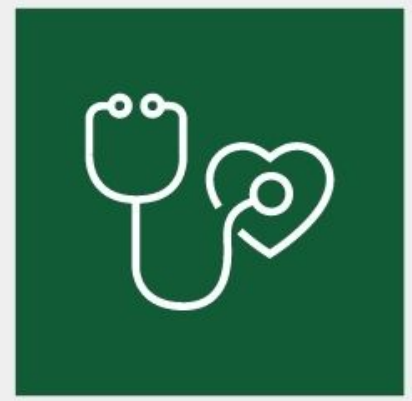

Cardiovascular Diseases \& Periodontitis

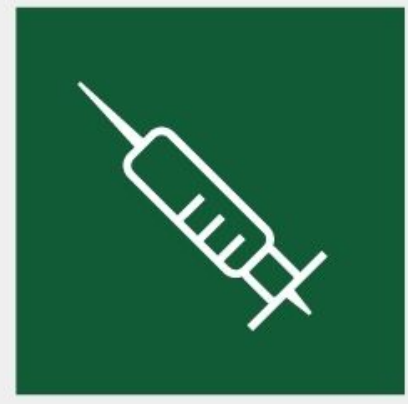

Diabetes \& Periodontitis

\section{Access now}

This Knowledge Hub is supported by Oral B. 


\title{
Evaluation of the short-term host response and biomechanics of an absorbable poly-4-hydroxybutyrate scaffold in a sheep model following vaginal implantation
}

\author{
Chantal M. Diedrich $^{1}$ (1) | Zeliha Guler $^{1}$ (i) | Lucie Hympanova $^{2,3}$ ～ Eva Vodegel $^{1}$ (1) | \\ Manuel Züindel $^{4,5}$ | Edoardo Mazza ${ }^{4,5}$ | Jan Deprest ${ }^{2}$ (D) | Jan Paul Roovers ${ }^{1}$
}

${ }^{1}$ Department of Obstetrics and Gynaecology, Center for Reproductive Medicine (AMC), Amsterdam UMC, University of Amsterdam, Amsterdam, The Netherlands

${ }^{2}$ Centre for Surgical Technologies, Biomedical Sciences Group, KU Leuven, Leuven, Belgium

${ }^{3}$ Third Faculty of Medicine, Institute for the Care of Mother and Child, Charles University, Prague, Czech Republic

${ }^{4}$ Institute of Mechanical Systems, ETH Zurich, Zurich, Switzerland

${ }^{5}$ Swiss Federal Laboratories for Materials Science and Technology, EMPA, Dübendorf, Switzerland

\section{Correspondence}

Zeliha Guler, Department of Obstetrics and Gynaecology, Amsterdam Reproduction and Development, Amsterdam UMC - location AMC, University of Amsterdam, Meibergdreef 9, Amsterdam, The Netherlands.

Email: zeliha.guler@amsterdamumc.nl

\section{Funding information}

Financial contribution was provided by Tepha, Inc., Lexington, MA, USA with unrestricted research grant

\begin{abstract}
Objective: To evaluate the host- and biomechanical response to a fully absorbable poly-4-hydroxybutyrate $(\mathrm{P} 4 \mathrm{HB})$ scaffold in comparison with the response to polypropylene (PP) mesh.

Design: In vivo animal experiment.

Setting: KU Leuven Center for Surgical Technologies.

Population: Fourteen parous female Mule sheep.

Methods: P4HB scaffolds were surgically implanted in the posterior vaginal wall of sheep. The comparative PP mesh data were obtained from an identical study protocol performed previously.

Main outcome measures: Gross necropsy, host response and biomechanical evaluation of explants, and the in vivo $\mathrm{P} 4 \mathrm{HB}$ scaffold degradation were evaluated at 60 - and 180 -days post-implantation. Data are reported as mean \pm standard deviation (SD) or standard error of the mean (SEM).

Results: Gross necropsy revealed no implant-related adverse events using P4HB scaffolds. The tensile stiffness of the $\mathrm{P} 4 \mathrm{HB}$ explants increased at 180-days $(12.498 \pm 2.66 \mathrm{~N} / \mathrm{mm}$ SEM $[p=0.019])$ as compared to 60 -days $(4.585 \pm 1.57 \mathrm{~N} / \mathrm{mm})$ post-implantation, while $\mathrm{P} 4 \mathrm{HB}$ degraded gradually. $\mathrm{P} 4 \mathrm{HB}$ scaffolds exhibited excellent tissue integration with dense connective tissue and a moderate initial host response. $\mathrm{P} 4 \mathrm{HB}$ scaffolds induced a significantly higher $\mathrm{M} 2 / \mathrm{M} 1$ ratio $(1.70 \pm 0.67 \mathrm{SD}$, score $0-4)$, as compared to PP mesh $(0.99 \pm 0.78 \mathrm{SD}$, score $0-4)$ at 180 -days.

Conclusions: $\mathrm{P} 4 \mathrm{HB}$ scaffold facilitated a gradual load transfer to vaginal tissue over time. The fully absorbable P4HB scaffold, in comparison to PP mesh, has a favorable host response with comparable load-bearing capacity. If these results are also observed at longer follow-up in-vivo, a clinical study using P4HB for vaginal POP surgery may be warranted to demonstrate efficacy.
\end{abstract}


K E Y W O R D S

biomechanics, degradable scaffold, host response, pelvic organ prolapse, poly-4-hydroxybutyrate, vaginal surgery

Tweetable abstract: Degradable vaginal P4HB implant might be a solution for treatment of POP.

\section{$1 \mid$ INTRODUCTION}

Pelvic organ prolapse (POP) is a common condition resulting from damage to the supportive structures of the pelvic floor. ${ }^{1,2}$ The annual incidence of surgery for POP is approximately 4.9 cases per 1000 women, with an overall lifetime risk for surgery of $11 \%{ }^{3,4}$ Synthetic permanent polypropylene (PP) meshes have been introduced for the surgical repair of POP to provide mechanical support to the pelvic floor by inducing a foreign body response. ${ }^{3,5}$ However, PP meshes have been associated with clinical complications. Even though PP meshes have been modified $^{6,7}$ and have resulted in a milder host response and better outcomes, ${ }^{8}$ the reputation of this technique has been damaged. The US Food and Drug Administration (FDA) re-classified vaginal POP meshes from class II to class III in 2016, and have not approved vaginal POP meshes since April 2019 in some countries, including the USA. The Scientific Committee on Emerging and Newly Identified Health Risks (SCENIHR) has recommended the identification of alternatives to PP, with a focus on biodegradable biomaterials to reduce the risk of long-term complications. ${ }^{9}$

Poly-4-hydroxybutyrate (P4HB) has been identified as a candidate material for vaginal POP surgery, ${ }^{10,11}$ with the hypothesis that a delayed absorbable scaffold will provide mechanical support while being gradually replaced by functional connective tissue. $\mathrm{P} 4 \mathrm{HB}$ is a biologically produced biosynthetic polymer ${ }^{12}$ that degrades to the human metabolite $4 \mathrm{HB}^{13}$ before being eliminated from the body completely. Several P4HB devices for soft tissue support have been cleared by the FDA ${ }^{14}$ and are used for clinical applications, including reconstructive surgery and tendon and ligament repair.

Knitted P4HB scaffolding provides good anatomical and functional outcomes in hernia repair. ${ }^{15}$ Although the forces involved are different, this procedure also provides load-bearing soft tissue correction, as in the case of POP. A previously performed in vitro study illustrated that vaginal fibroblast on $\mathrm{P} 4 \mathrm{HB}$ scaffolds generated a more favourable cellular response, followed by collagen deposition, compared with PP. ${ }^{10}$ In addition, this study identified a P4HB knit design that improved cellular behaviour.

Therefore, $\mathrm{P} 4 \mathrm{HB}$ is seen as a promising candidate material for pelvic floor surgery. In the present study the aim was to further evaluate the host response and biomechanics of fully degradable P4HB scaffolds using sheep as an animal model for vaginal POP surgery. ${ }^{16,17}$ The outcomes of P4HB scaffolding were compared with data for PP mesh obtained from an identical study performed by our group.

\section{$2 \mid$ METHODS}

\section{1 | Implants}

Based on the previously performed in vitro study, ${ }^{10}$ we selected a knitted, monofilament $\mathrm{P} 4 \mathrm{HB}$ scaffold design with an implant thickness of $0.28 \mathrm{~mm}$, a fibre diameter of $100 \mu \mathrm{m}$ and a pore size of $2.22 \mathrm{~mm}^{2}$. For comparison, retrospective data obtained with lightweight PP (Restorelle; Coloplast, Humlebaek, Denmark) with an implant thickness of $0.34 \mathrm{~mm}$, a fibre diameter of $80 \mu \mathrm{m}$ and a pore size of $3.1 \mathrm{~mm}^{2}$, were used.

\subsection{Animals, surgical procedures and study design}

Animals, anaesthesia and surgical procedures are detailed in Appendices S1 and S2. Fourteen parous female Mule sheep (7 years old, weighing $51.5 \pm 5.7 \mathrm{~kg}$ ) were included. The animals used in this study were maintained and treated according to experimental protocols (P057/2014, P064/2013 and P051/2016) approved by the Ethics Committee on Animal Experimentation of the Faculty of Medicine, KU Leuven. In this study only sheep were used for investigation; patients were not included. Ewes were randomly divided into two groups, with each group including seven sheep. All sheep underwent rectovaginal surgery for the implantation of $\mathrm{P} 4 \mathrm{HB}$ scaffolds. The surgical procedure was carried out according to the previously described method ${ }^{4}$ by the same experienced surgeon (LH). Briefly, the rectovaginal septum was dissected following hydro-dissection. P4HB scaffolds $(35 \times 35 \mathrm{~mm})$ were fixed with interrupted non-degradable 3/0 PP sutures (Prolene; Ethicon, Raritan, NJ, USA) at the corners and halfway along each side (Figure 1). The vaginal wall was closed with a running 3/0 polyglactin 910 suture (Vicryl; Ethicon). Animals were checked for postoperative complications and housed until 1 week after surgery at the animal facility and then at the farm, with unrestricted access to food, water and with free access to open space. The ewes were killed at 60 or 180 days after surgery. 
(A) Vaginal Implantation

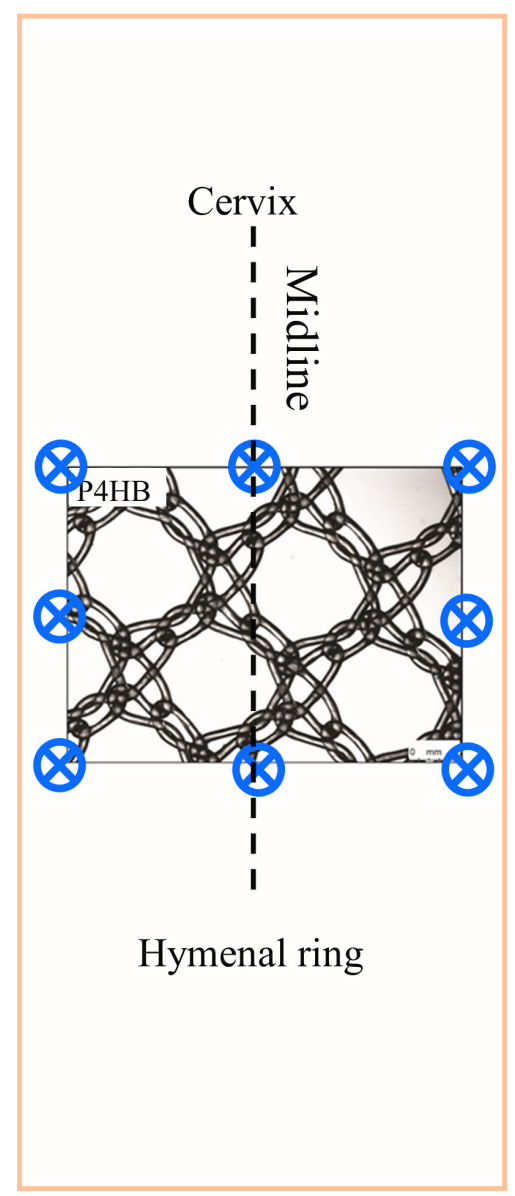

P4HB

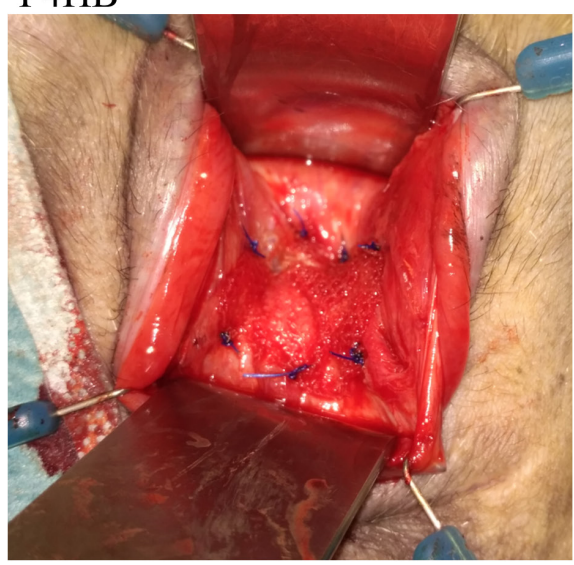

(B) Post-Implantation

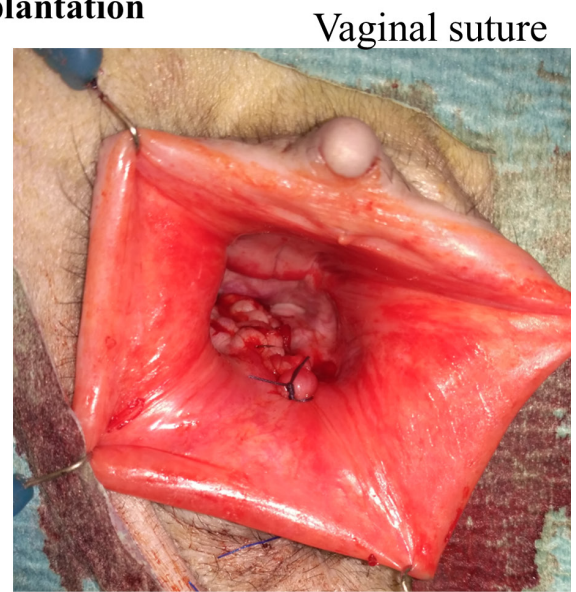

$\begin{array}{ll}\mathrm{P} 4 \mathrm{HB} & \text { (C) Post-Explantation }\end{array}$
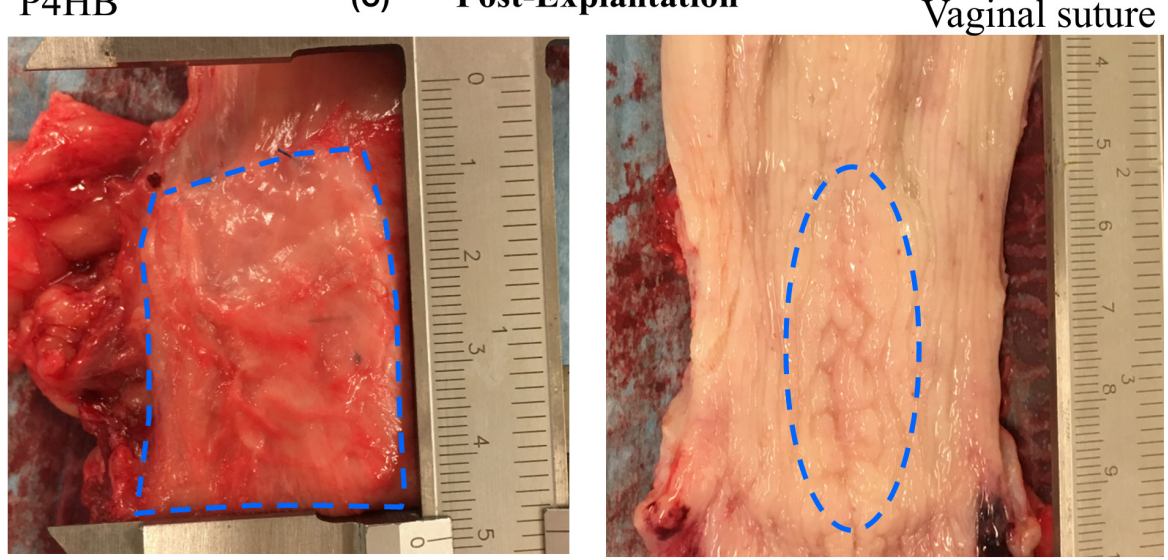

F I G U R E 1 (A) Schematic and (B) photographic representation of poly-4-hydroxybutyrate (P4HB) vaginal implantation in the posterior compartment. Fixation points using non-resorbable polypropylene (PP) 3/0 sutures and vaginal closure using a running closure with $3 / 0$ polyglactin 910 (Vicryl). (C) After en bloc excision of the vagina: the left panel illustrates the subcutaneous view with the remaining P4HB material; the right panel shows the mucosal side of the vagina with the healed vaginal closure

\subsection{Harvesting implants}

Ewes were premedicated with the intramuscular administration of $1 \mathrm{ml} / 50 \mathrm{~kg}$ xylazine and killed with intravenous pentobarbital (20 ml/50 kg Release; Ecuphar, Oostkamp, Belgium). ${ }^{4}$ Gross anatomical examination of the explanted vagina was performed using the following parameters: (i) fluid collection; (ii) exposure of the implant; (iii) synechiae; and (iv) signs of infection. Any shrinkage of the implant was calculated by measuring the length and the width of the scaffold. Vaginal explants (vaginal tissue/ P4HB implant complex) were dissected into four pieces for assessing both active and passive biomechanical properties, in vivo degradation of the $\mathrm{P} 4 \mathrm{HB}$ scaffold and histomorphology.

\section{4 $\quad$ Outcome measurements}

\subsection{1 $\quad$ Before implantation}

Mechanical properties of the implant before the implantation Before the implantation, the P4HB scaffold and PP mesh were subjected to uniaxial testing under dry conditions according to a standardised protocol. ${ }^{18}$ Details of the uniaxial testing are provided in Appendix S3.

\subsubsection{After implantation}

\section{Active biomechanical properties}

Longitudinal vaginal strips $(3 \times 7 \mathrm{~mm})$ from explants were dissected, weighed and immediately suspended in individual organ baths containing fresh Krebs solution. ${ }^{4}$ Samples were pre-tensioned to $0.5 \mathrm{mN}$ and equilibrated for $60 \mathrm{~min}$ before measurement. The samples were subjected to contractile stimulation by $80 \mathrm{mM} \mathrm{KCl}$. Contractile forces were recorded using custom-made software. Measurements were analysed using ORIGIN (OriginLab Corporation, Northampton, MA, USA). All values were normalised to the sample weight, transducer calibration and gravitation constant.

\section{Passive biomechanical properties}

Uniaxial tensiometry on the vaginal explants was performed using a uniaxial tensiometer (ZwickRoell, Ulm, Germany) with a $200-\mathrm{N}$ load cell. Posterior middle vaginal 
tissue from the same sheep was used as a control. Samples were cut longitudinally $(10 \times 30 \mathrm{~mm})$, clamped tension-free and the zero elongation was defined as the clamp-to-clamp distance at preloading $(0.1 \mathrm{~N})$. The samples were loaded to failure with an elongation rate of $10 \mathrm{~mm} / \mathrm{min}$. The strain was calculated by dividing the elongation by the clamp-toclamp distance; the stress was calculated by dividing the force applied by the cross-sectional area. ${ }^{19}$ The stiffness $(\mathrm{N} /$ $\mathrm{cm}^{2}$ ) of the specimens was determined by the slope of the stress-strain curve in the comfort zone using TESTXPERT II (ZwickRoell). ${ }^{18}$

\section{In vivo degradation of the $\mathrm{P} 4 \mathrm{HB}$ implant}

The in vivo degradation of $\mathrm{P} 4 \mathrm{HB}$ scaffolds was determined by the change in molecular weight $(\mathrm{Mw})$ via gel permeation chromatography (GPC) analysis and by morphological scaffold changes via scanning electron microscopy (SEM) (JSM6700F; JEOL, Akishima, Tokyo, Japan). This was performed after vaginal tissue digestion. ${ }^{20}$ Details of the tissue digestion and analysis of GPC and SEM are provided in Appendix S4.

\section{Histomorphology}

Details of histology and immunohistochemistry (IHC) staining and scoring are provided in Appendix S5 (Figure S1; Table S1). Tissue integration of the P4HB scaffolds was evaluated from SEM images of the vaginal explants. Histology sections were stained with haematoxylin and eosin $(\mathrm{H} \& \mathrm{E})$ and Masson's trichrome to quantify the foreign body giant cells (FBGC), polymorphonuclear cells (PMN), blood vessels and connective tissue. IHC staining was performed for the detection of neovascularisation (CD34), neuronal network (PGP 9.5), myofibroblasts and smooth muscle cells ( $\alpha$-SMA), leukocytes (CD45), M1 (HLA-DR) and M2 (CD163) macrophages. The M2/M1 ratio was calculated. Semiquantitative assessment of all samples was performed by two individual researchers blinded for both time points, using a previously desined grading scale. ${ }^{4,21}$

\subsection{Statistical analysis}

Statistical analysis on $\mathrm{P} 4 \mathrm{HB}$ and $\mathrm{PP}$ data was performed with PRISM 7.0 (GraphPad Software, San Diego, CA, USA). Data normality was tested by Kolmogorov-Smirnov test. A two-way analysis of variance (ANOVA) was used for normally distributed data and multiple comparisons between individual groups were made using Tukey's test. The Kruskal-Wallis test followed by Dunn's post hoc test was used for not normally distributed data. Data are reported as means \pm standard deviations or standard errors of the mean. The significance level was defined as $p<0.05$.

\section{$3 \quad$ RESULTS}

\section{1 $\quad$ Before implantation}

\subsubsection{Mechanical characteristics of the implants}

The P4HB scaffold and PP mesh exhibited similar behaviour under cyclic uniaxial load (Figure 2), with strong inelastic deformation in the first cycle followed by rapid stabilisation. However, the membrane stiffness of the PP mesh is significantly $(p<0.01)$ higher compared with the P4HB scaffold after the first and tenth cycles. A decrease in the stiffness of the PP mesh ${ }^{22}$ was observed after ten cycles, in contrast to the $\mathrm{P} 4 \mathrm{HB}$ scaffold, which exhibited a relatively small increase in
(A)
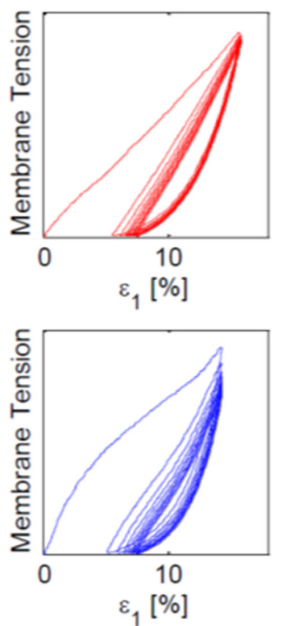

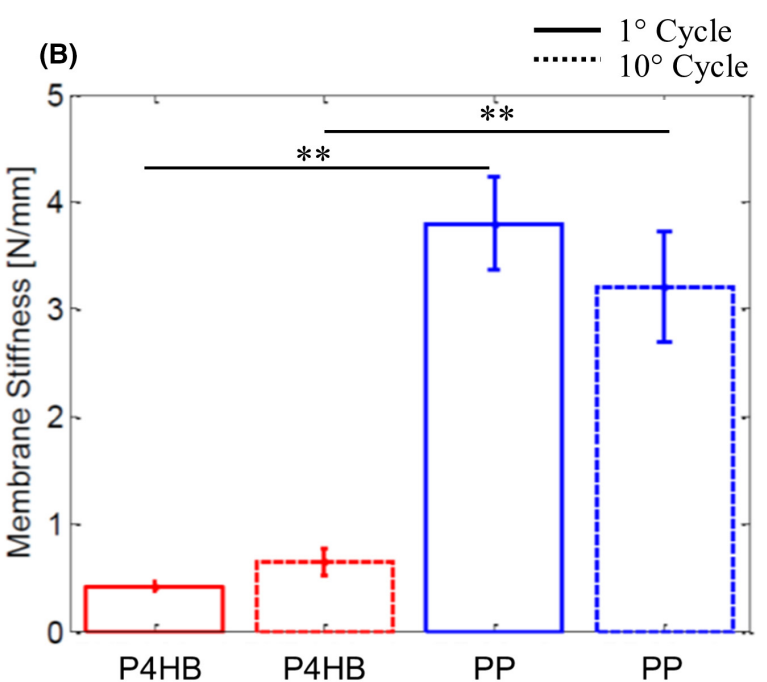

F I G U R E 2 (A) Typical behaviour of poly-4-hydroxybutyrate (P4HB, red) implants $(n=4)$ and polypropylene (PP, blue) implants $(n=4)$ when subjected to a cyclic uniaxial tensile test. (B) Tangent membrane stiffness of P4HB (red) and polypropylene (PP, blue) evaluated at the beginning of the loading curve in the first and the tenth load cycle for tests in dry conditions at room temperature. Error bars represent means \pm SDs. An ANOVA test was used to test for differences between groups. Values differing significantly are indicated with asterisks: ${ }^{* *} p<0.01$ 
its stiffness after cyclic mechanical loading. However, the changes in membrane stiffness for PP and P4HB after ten cycles was not statistically significant.

\section{2 $\quad$ After implantation}

\subsubsection{Gross anatomical examination of the explanted vagina and implant contraction}

All implants were well incorporated in the deeper vaginal tissue layers, without any signs of encapsulation. Exposure of P4HB scaffold, signs of infection or fluid collection were not observed at both 60 and 180 days post-implantation. Sheep implanted with PP mesh $(n=6)$ developed vaginal synechiae $(n=3)$. P4HB scaffolds were intact, without macroscopic deformation. The shrinkage (\% area) of the implants after 60 days and 180 days was $52.2 \pm 10.41 \%$ SD and $45.9 \pm 7.95 \%$ SD, respectively. The shrinkage of the PP mesh at 60 and 180 days post-implantation was reported previously: $29.6 \pm 7.8 \% \mathrm{SD}$ and $46.7 \pm 14.2 \% \mathrm{SD}$, respectively.

\subsection{2 | Active biomechanical properties}

Vaginal tissue contraction (Figure 3 ) in response to $\mathrm{KCl}$ was higher at 180 days post-implantation $(226.90 \pm 79.08 \mathrm{mN}$ SEM) in comparison with 60 days post-implantation $(148.53 \pm 22.76 \mathrm{mN}$ SEM). Vaginal tissue exhibited higher contractile function after $\mathrm{P} 4 \mathrm{HB}$ scaffold implantation, compared with post-PP mesh implantation $(37.87 \pm 18.99 \mathrm{mN}$ SEM at 60 days post-implantation;

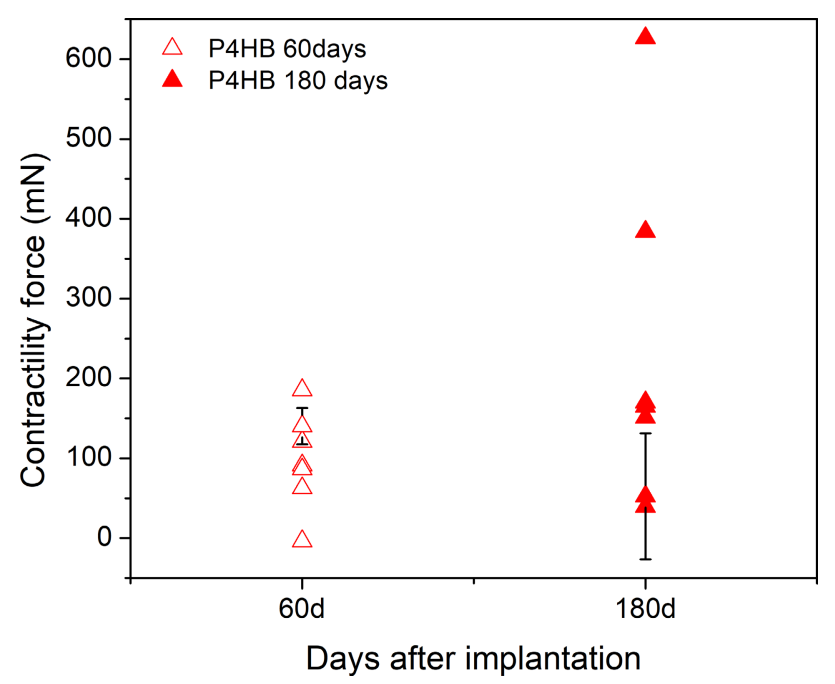

F I G U R E 3 Vaginal wall contractility after implantation with poly4-hydroxybutyrate $(\mathrm{P} 4 \mathrm{HB})$ at 60 days post-implantation $(n=7)$ and at 180 days post-implantation $(n=7)$. Error bars represent means \pm standard errors of the mean (SEM). A Kruskal-Wallis test was used to test for a difference between the time points. No significant difference was found between 60 and 180 days post-implantation
$199.49 \pm 71.56 \mathrm{mN}$ SEM at 180 days post-implantation); however, the difference at both time points was not statistically significant.

\subsubsection{Passive biomechanical properties}

The biomechanical properties of the vaginal explants and control tissue were compared at 60 and 180 days postimplantation (Figure 4). At 60 days post-implantation the P4HB explants exhibited significantly lower stiffness values compared with the control tissue $(4.58 \pm 1.57 \mathrm{~N} / \mathrm{mm}$ SEM versus $11.49 \pm 1.95 \mathrm{~N} / \mathrm{mm} \mathrm{SEM}, p=0.024)$. The stiffness of the explants after 180 days post-implantation increased significantly $(12.498 \pm 2.66 \mathrm{~N} / \mathrm{mm}, p=0.019)$ compared with 60 -days post-implantation and exhibited comparable stiffness with the control tissue $(11.343 \pm 1.96 \mathrm{~N} / \mathrm{mm} \mathrm{SEM})$. According to the ball-burst test, which is not directly comparable with uniaxial tensile testing, there were no statistically significant changes in the stiffness values of the PP explants at both time points. ${ }^{4}$

\subsubsection{In vivo degradation of the $\mathrm{P} 4 \mathrm{HB}$ scaffold}

The degradation of the $\mathrm{P} 4 \mathrm{HB}$ scaffold was determined by a change in molecular weight $(\mathrm{Mw})$ over time (Figure 5A). The average $\mathrm{Mw}$ of the $\mathrm{P} 4 \mathrm{HB}$ scaffold gradually decreased over time: $279 \pm 3,201 \pm 5$ and $104 \pm 7 \mathrm{kDa}$ SD at 0,60 and 180 days post-implantation, respectively. The integrity and

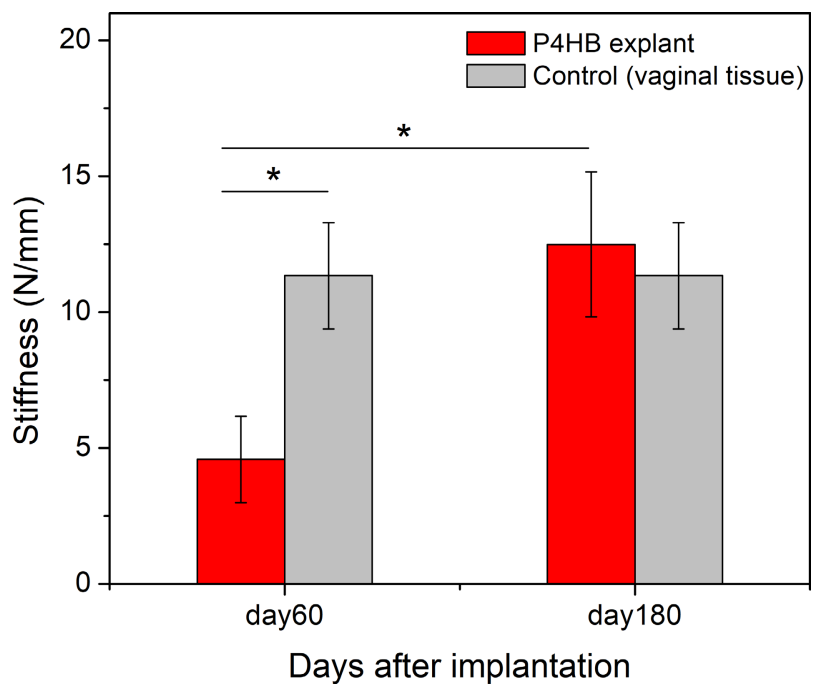

F I G U R E 4 Stiffness (N/mm) of vaginal poly-4-hydroxybutyrate (P4HB) explants ( $n=7$ at 60 days post-implantation; $n=5$ at 180 days post-implantation) compared with control tissue (tissue harvested from posterior middle vagina) ( $n=7$ for both time points) at 60 and 180 days post-implantation. Error bars represent standard errors of the mean (SEM). A Kruskal-Wallis test was used to test for differences between groups and time points. Values differing significantly from the control are indicated with asterisks: ${ }^{*} p<0.05$ 
(A)

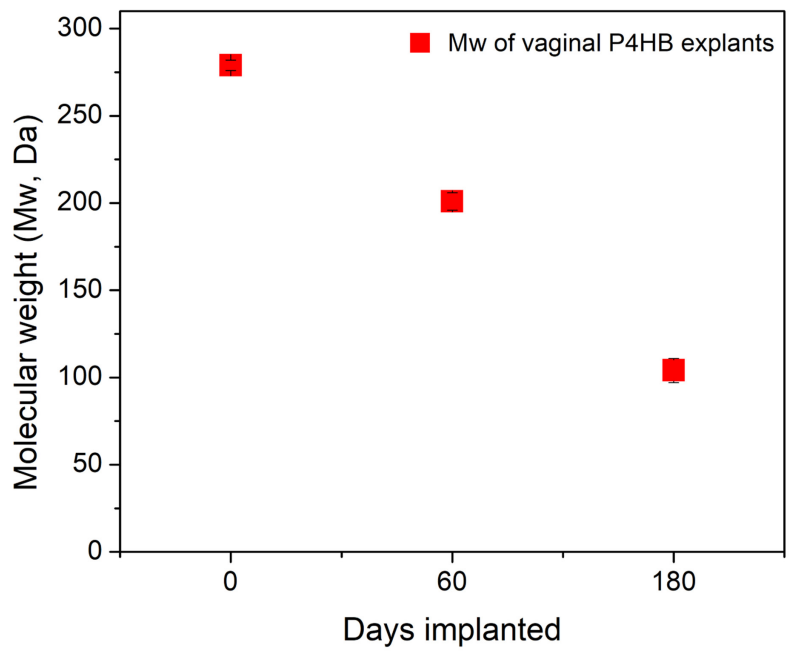

(B)
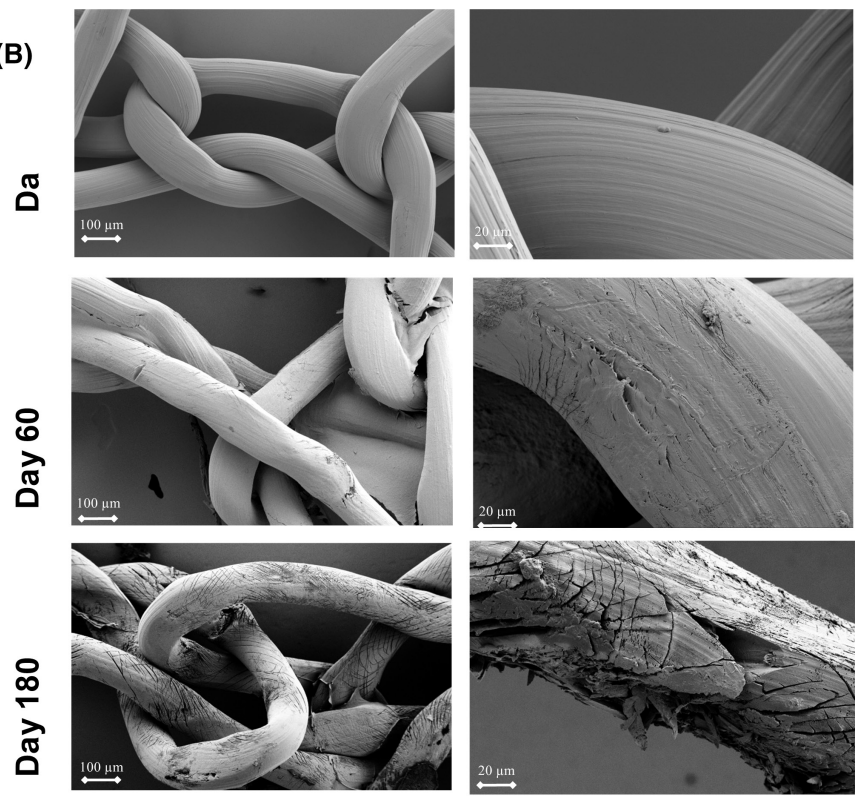

(C)
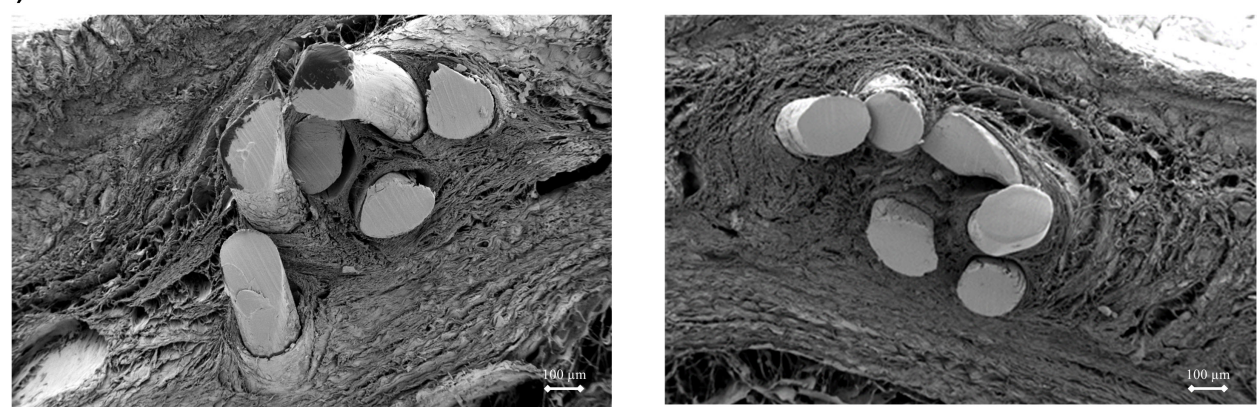

F I G U R E 5 In vivo degradation (A, B) and tissue integration (C) of vaginal poly-4-hydroxybutyrate (P4HB) explants at 0, 60 and 180 days postimplantation. (A) Change in molecular weight according to gel permeation chromatography ( $n=7$ for each time point); data points represent mean values per time point and error bars represent \pm standard deviation (SD). (B) Scanning electron microscopy images illustrating microstructural change as a result of degradation over time. (C) Scanning electron microscopy images showing the integration of the P4HB implant in vaginal tissue at 60 and 180 days post-implantation

morphological changes of the implant were visualised by SEM (Figure 5B). The monofilament of the P4HB scaffold kept its overall macroscopic integrity at both time points. SEM images revealed the formation of fibre surface erosion over time. At 60 days, there were only superficial scratches on the fibres, which gradually progressed into surface fissuring over 180 days post-implantation.

\subsection{5 | Histomorphology}

The P4HB scaffold maintained its integrity after 60 and 180 days post-implantation and showed good integration within the submucosa of the vaginal tissue (Figure 5C). The $\mathrm{P} 4 \mathrm{HB}$ scaffold could be identified in between the lamina propria and muscularis layer in the H\&E-stained samples (Figure 6). There was no significant difference in the presence of FBGCs at the border of the implant between both time points (FBGC score: $0.93 \pm 0.42 \mathrm{SD}$ at 60 days post-implantation and $0.73 \pm 0.54 \mathrm{SD}$ at 180 days postimplantation) (Figure 6A). A decrease in the presence of
PMNCs was observed over time; however, this difference was not significant (PMNC score: $2.06 \pm 0.70 \mathrm{SD}$ at 60 days post-implantation and $1.65 \pm 0.83 \mathrm{SD}$ at 180 days postimplantation) (Figure 6B). There was significantly higher inflammatory cell infiltration around the P4HB scaffold as compared with the PP mesh at both 60 days post-implantation (PMNC score: $\mathrm{P} 4 \mathrm{HB}, 2.06 \pm 0.70 \mathrm{SD}$; PP, $0.60 \pm 0.31 \mathrm{SD}$ ) and 180 days post-implantation (PMNC score: $\mathrm{P} 4 \mathrm{HB}, 1.65 \pm 0.83$ SD; PP, $0.32 \pm 0.10 \mathrm{SD}$ ) (Figure S2). ${ }^{4}$ There was no significant difference in the vessel count around the P4HB scaffold at 60 and 180 days post-implantation based on H\&E staining (Figure 6C). However, the PP mesh exhibited a higher number of vessels compared with the P4HB scaffold at both time points (Vessel score: P4HB versus PP, $0.87 \pm 054$ SD versus $1.52 \pm 0.46 \mathrm{SD}$, at 60 days post-implantation; $\mathrm{P} 4 \mathrm{HB}$ versus $\mathrm{PP}, 0.78 \pm 0.53 \mathrm{SD}$ versus $1.96 \pm 0.32 \mathrm{SD}$, at 180 days postimplantation) (Figure S2). At 60 days post-implantation, $\mathrm{P} 4 \mathrm{HB}$ scaffolds were surrounded with newly formed connective tissue with aligned collagen fibres. After 180 days postimplantation the collagen fibres matured, as indicated by the darker blue staining, and the density increased (Figure 6D). 
60 days

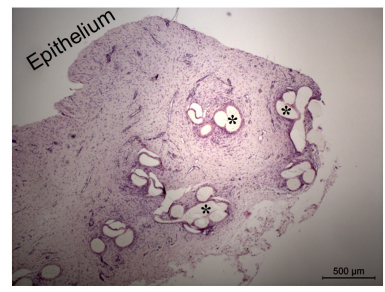

H\&E

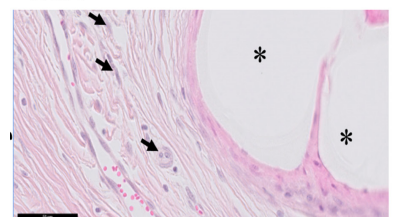

MT

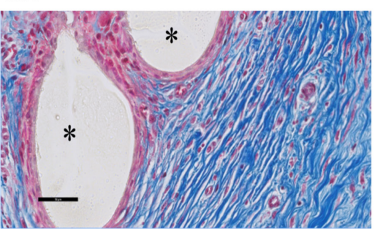

\section{H\&E}

180 days

H\&E
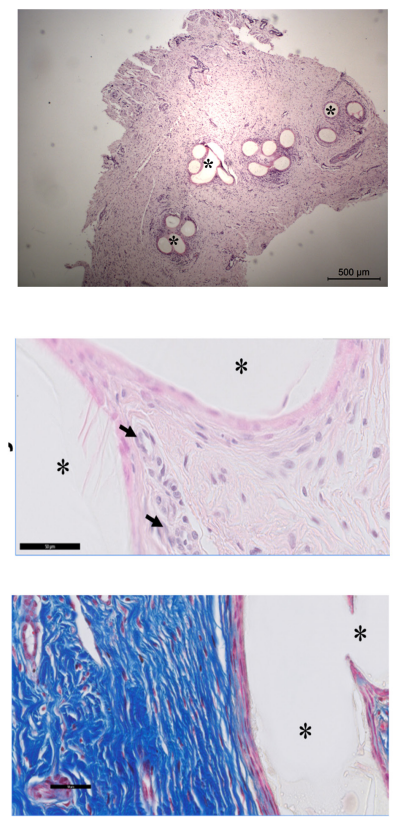
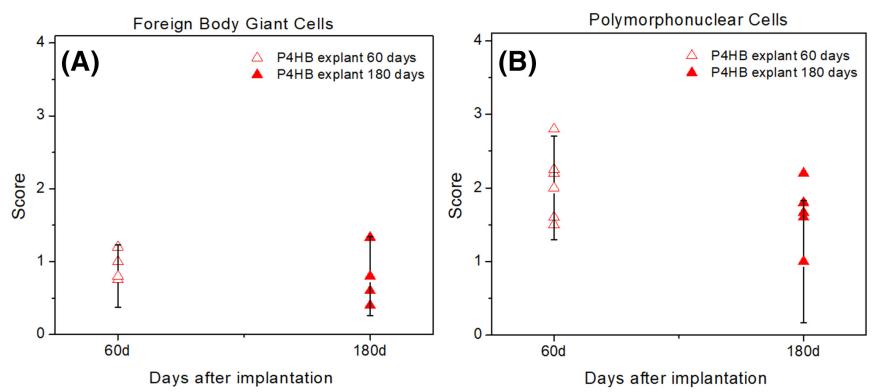

Collagen

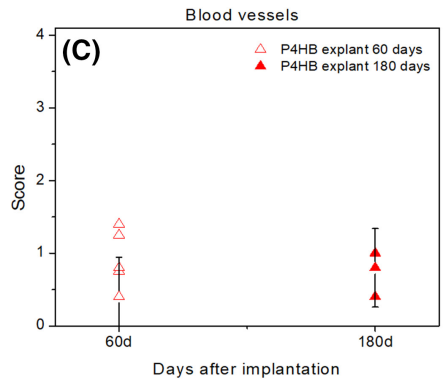

F I G U R E 6 The panels on the left present representative images of haem

\begin{abstract}
500 $500 \mu \mathrm{m})$, showing the localization of the poly-4-hydroxybutyrate (P4HB) scaffolds in the vaginal tissue. Also shown are representative figures of $\mathrm{H} \& \mathrm{E}$ and Masson's trichrome (MT) staining of P4HB vaginal explants used for scoring (scale bar, $50 \mu \mathrm{m}$ ). Implant structures are indicated with asterisks and foreign body giant cells are indicated with black arrows. MT staining: collagen is stained blue, cell nuclei are stained black and the background is stained red. On the right: host response to vaginal P4HB implants based on H\&E and MT staining, in terms of foreign body giant cells (A), polymorphonuclear cells (B), blood vessels (C) and collagen content (D) at 60 and 180 days post-implantation. At 60 days post-implantation, $n=7$ samples; at 180 days postimplantation, $n=5$ samples. Error bars represent means \pm standard deviations (SD). A Kruskal-Wallis test was used to test for differences between time points; no significant differences were found
\end{abstract}

There was no significant difference of neovascularisation (Figure 7B), neuronal ingrowth (Figure 7F) and myofibroblast differentiation (Figure $7 \mathrm{H}$ ) between 60 and 180 days post-implantation with the $\mathrm{P} 4 \mathrm{HB}$ scaffold. The presence of leukocytes (CD45) at 180 days post-implantation (score $1.4 \pm 0.28 \mathrm{SD}$ ) was significantly lower compared with the level at 60 days post-implantation (score $2.05 \pm 0.55 \mathrm{SD}$ ) after the P4HB scaffold implantation (Figure 7D). At 180 days postimplantation a more widespread infiltration area was CD45 positive, whereas at 60 days post-implantation this was more visible at the implant border. Compared with the PP mesh, leukocyte infiltration at the $\mathrm{P} 4 \mathrm{HB}$ tissue-scaffold interface was significantly higher (PP, $1.29 \pm 0.36 \mathrm{SD})$ at 60 days post-implantation and significantly lower (PP: $2 \pm 0.36 \mathrm{SD})$ at 180 days post-implantation (Figure S3). At 180 days postimplantation, the $\mathrm{P} 4 \mathrm{HB}$ scaffold exhibited significantly lower myofibroblast differentiation compared with PP (PP, $2.41 \pm 0.26 \mathrm{SD}$; P4HB, $1.62 \pm 0.56 \mathrm{SD}$ ) (Figure S3).

There was a statistically significant decrease observed in macrophage type-1 (M1) infiltration to the P4HB scaffold between 60 and 180 days post-implantation (Figure 8B). At 60 days post-implantation, M1 infiltration was predominant $(2.02 \pm 0.62 \mathrm{SD})$ at the P4HB scaffold-tissue interface, compared with 180 days post-implantation (1.56 $\pm 0.59 \mathrm{SD})$. No statistically significant difference in M2 infiltration was observed between 60 days post-implantation $(1.97 \pm 0.85$
SD) and 180 days post-implantation $(2.24 \pm 0.66 \mathrm{SD})$. The M2/M1 ratio was significantly $(p<0.01)$ higher at 180 days post-implantation $(1.70 \pm 0.67 \mathrm{SD})$ compared with 60 days post-implantation $(0.91 \pm 0.60 \mathrm{SD})$ of the $\mathrm{P} 4 \mathrm{HB}$ scaffold (Figure 8F). Compared with the retrospective PP mesh data, the M2/M1 ratio at 180 days post-implantation was significantly higher with the P4HB scaffold (Figure S3; PP, $0.92 \pm 0.17 \mathrm{SD}$ and $0.99 \pm 0.78 \mathrm{SD}$ at 60 and 180 days postimplantation, respectively).

\section{DISCUSSION}

In this study, well-remodelled vaginal tissue with enhanced biomechanical properties after transvaginal implantation of $\mathrm{P} 4 \mathrm{HB}$ scaffolds was obtained in a sheep model. We have evaluated the host response, biomechanical properties and degradation profile of explants at 60 and 180 days postimplantation. With gross anatomical examination we did not observe any adverse event, such as infection or exposure. The stiffness of the vaginal $\mathrm{P} 4 \mathrm{HB}$ scaffold increased over time, whereas the polymer underwent significant degradation. The $\mathrm{P} 4 \mathrm{HB}$ scaffold resulted in a moderate host response and tissue remodelling, demonstrated by an increased M2/ M1 ratio, low myofibroblast differentiation and the formation of densely packed collagen over time. 
(A)

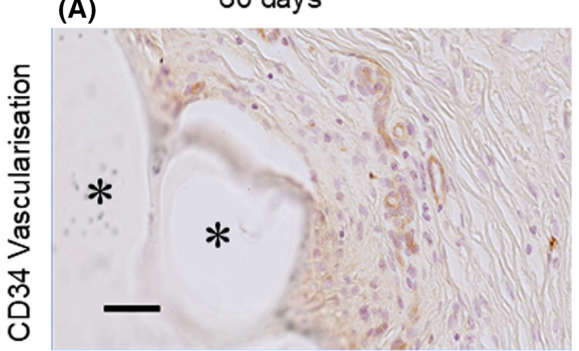

(C)

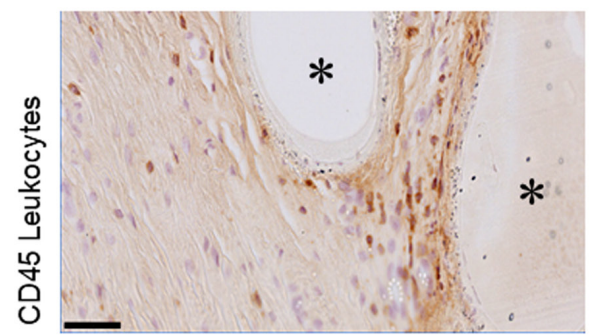

(E)

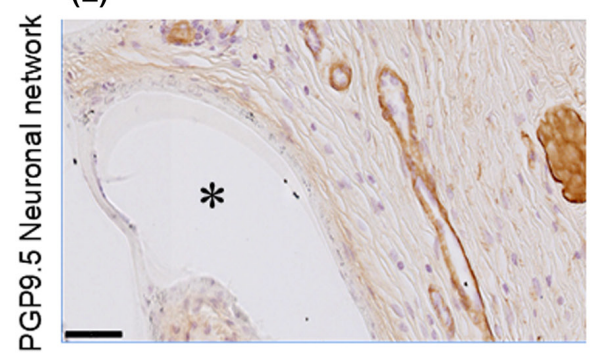

(G)

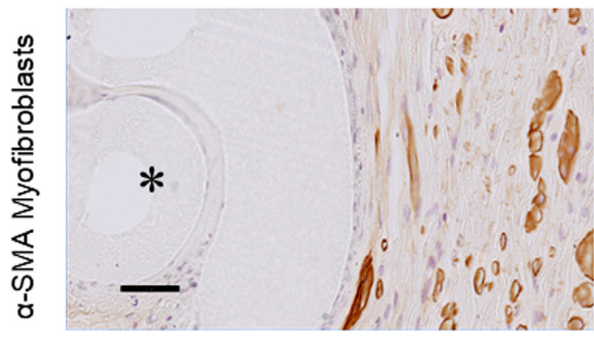

180 days
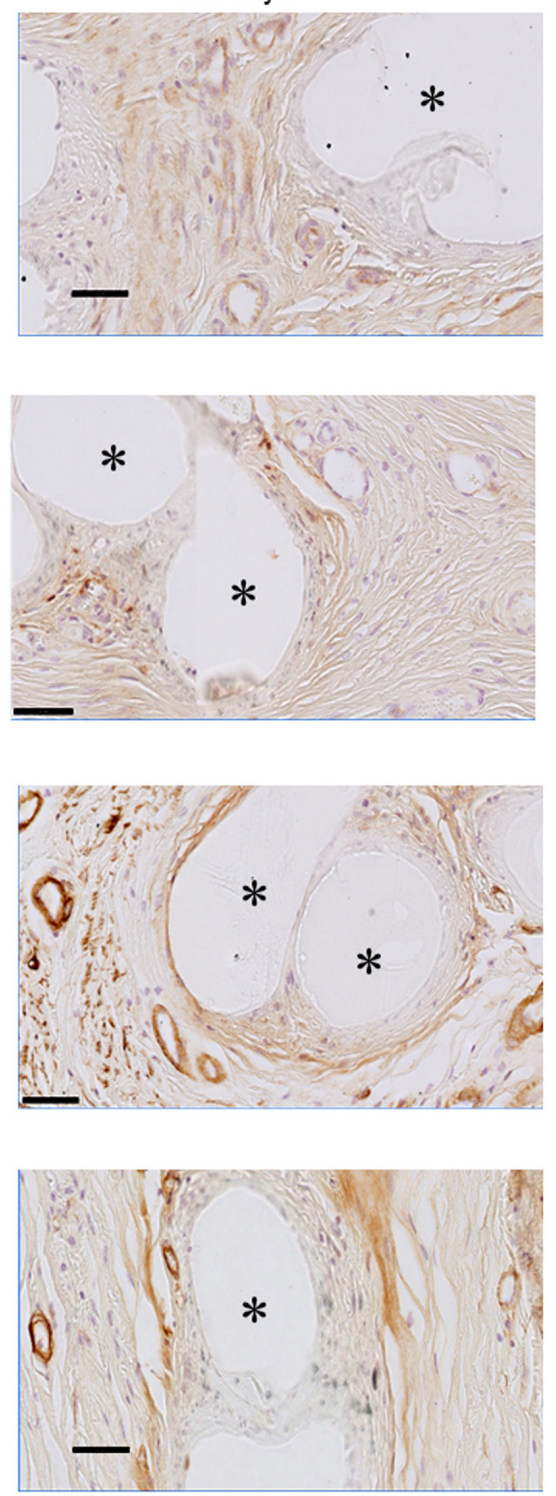

(B)

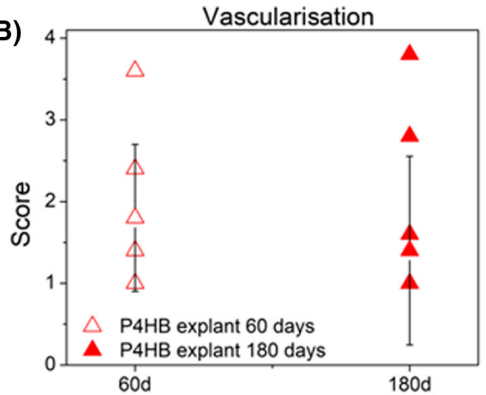

(D)

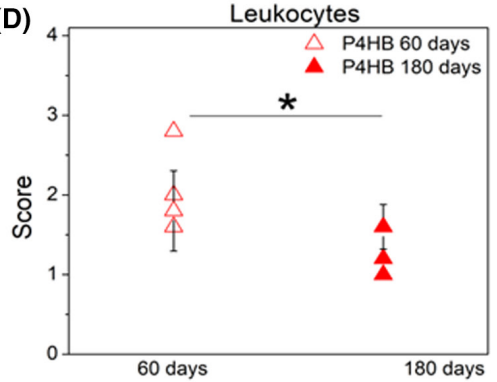

(F)

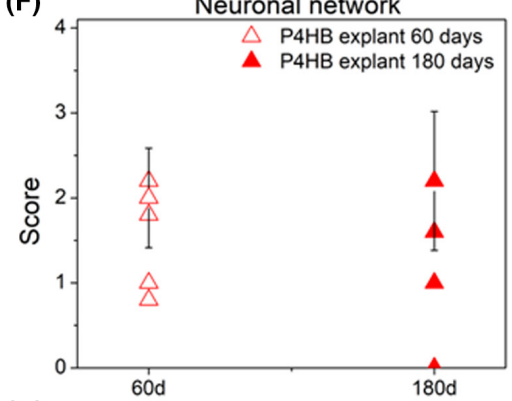

(H)

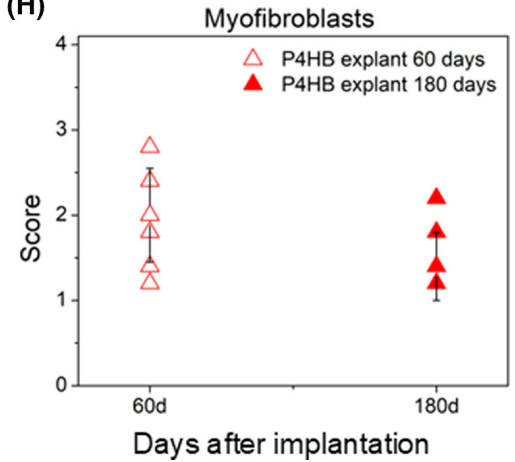

F I G U R E 7 (A, C, E, G) Representative images of immunostained samples at 60 and 180 days post-implantation. Implant structures are represented by asterisks. (B, D, F, H) Scoring results for endothelial cells of the blood vessels (CD34), leukocytes (CD45), neurons (PGP9.5) and myofibroblast and smooth muscle cells (smooth $\alpha$-SMA) of poly-4-hydroxybutyrate (P4HB) vaginal explants at 60 and 180 days post-implantation. At 60 days postimplantation, $n=7$ samples; at 180 days post-implantation, $n=5$ samples. Error bars represent means \pm standard deviations (SD). A Kruskal-Wallis statistical test was used to test for differences between time points. Values differing significantly are indicated with asterisks: ${ }^{*} p<0.05$

The initial inflammatory response to the $\mathrm{P} 4 \mathrm{HB}$ scaffold was greater compared with the PP mesh, and this changed after 180 days where fewer leukocytes and a higher M2/M1 ratio was seen with the P4HB scaffold. The inflammatory response to the TIGR Matrix hybrid implant, which has a different composition compared with $\mathrm{P} 4 \mathrm{HB}$ but a similar degradation profile, also became milder over time and resulted in thicker tissue formation, compared with the PP mesh. ${ }^{23}$
The P4HB scaffolds were intact and well integrated within the vaginal tissue, without any signs of encapsulation or exposure. This might be related to the exceptionally low membrane stiffness of the P4HB scaffold. Constant applied load after implantation can cause an increase in implant stiffness, which in turn may lead to vaginal degeneration and eventually exposure. ${ }^{24,25}$ One can predict no or limited exposures with the use of the $\mathrm{P} 4 \mathrm{HB}$ scaffold, as even after ten cycles of mechanical 

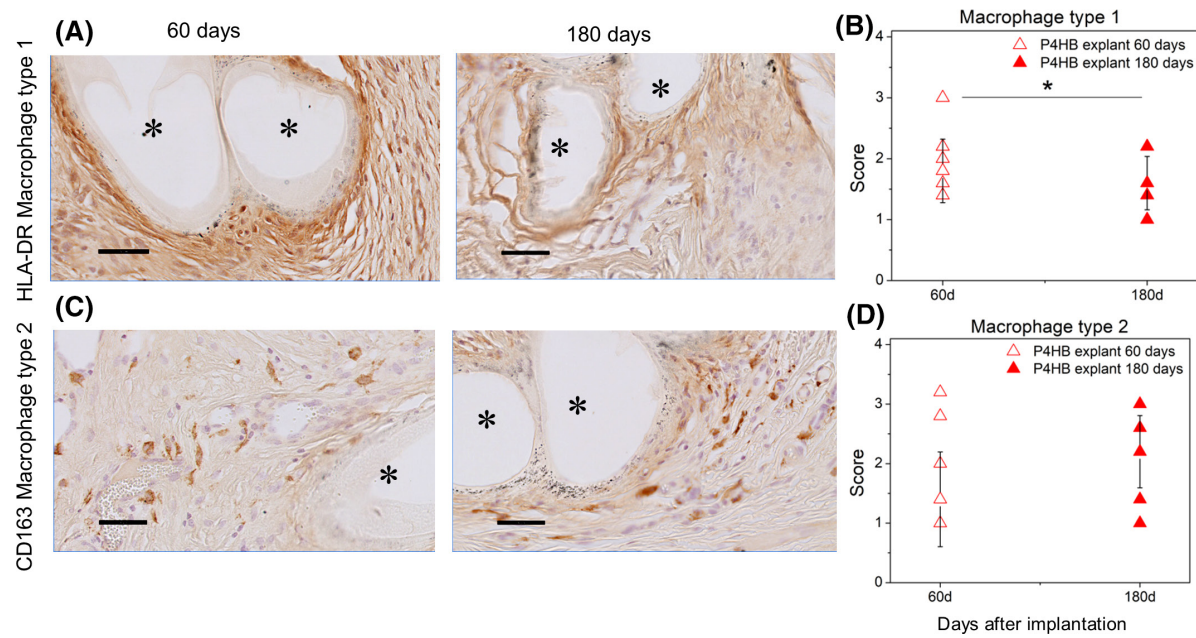

(E)

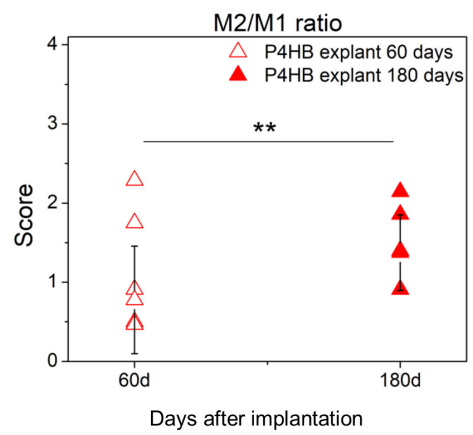

F I G U R E 8 Representative images of immunostained samples and scoring results for macrophage type 1 (HLA-DR) and macrophage type 2 (CD163) of poly-4-hydroxybutyrate (P4HB) vaginal explants at 60 and 180 days post-implantation. Implant structures are represented by asterisks in (A) and (C). At 60 days post-implantation, $n=7$ samples; at 180 days post-implantation, $n=5$ samples. Error bars represent means \pm standard deviations (SD). A Kruskal-Wallis statistical test was used to test for differences between time points. Values differing significantly between time points are indicated with asterisks: ${ }^{*} p<0.05 ;{ }^{* *} p<0.01$

loading there was only a slight increase in the stiffness of the P4HB scaffold.

The gradual absorption of $\mathrm{P} 4 \mathrm{HB}$ provided a good balance between implant degradation and tissue formation. The rapid degradation of implants may be associated with poor clinical outcomes because of the weakness of the remodelled tissue. For instance, it was reported that degradable polyglactin-910 implants disappeared within a 6-week period after vaginal implantation, ${ }^{26}$ which resulted in $25 \%$ of recurrent cystoceles after 12 months. De Tayrac et al. ${ }^{27}$ found that polylactic acid (PLA) implants already lost most of the mass after 1.5 months in vitro, where degradation is slower compared with in vivo. Apart from preclinical studies for synthetic degradable materials, there are other examples of clinically used degradable xenografts in transvaginal surgery, such as porcine dermis or porcine small intestinal submucosa like InteXEN ${ }^{28}$ and Surgisis..$^{\circ}$ However, with the rapid degradation of xenografts, the load-bearing capacity of vaginal tissue was insufficient in the long term, which resulted in recurrent prolapse. ${ }^{28}$ Therefore, a sufficient degradation profile of a newly designed implant is necessary to maintain pelvic floor support over time.

P4HB degrades primarily by bulk hydrolysis, wherein water molecules diffuse into the polymer and cleave the polymer chains, ${ }^{30}$ and secondly by enzyme-catalysed hydrolysis that causes a small amount of surface erosion. Therefore, the SEM images of the P4HB scaffold show an intact construct without any sign of a reduction in fibre size. P4HB degradation results in a steady loss of polymer molecular weight and a decrease of strength but not in a loss of mass or volume over time. ${ }^{10,30,31}$ In contrast to strength retention, the stiffness of the explants was at least ten times higher when compared with the initial stiffness of the $\mathrm{P} 4 \mathrm{HB}$ scaffold. This suggests that the remodelling and regeneration of the vaginal tissue contributes to increased tissue stiffness. ${ }^{23}$
The tissue components such as collagen contribute to the biomechanical properties of the tissue by allowing the tissue to resist deformation under mechanical force. ${ }^{32}$ As the $\mathrm{P} 4 \mathrm{HB}$ scaffold gradually degrades, it induces functional vaginal tissue with mechanical integrity. The functionality of the vagina, which can be determined by its ability to actively contract through smooth muscle activity, may change after implantation. The presence of an implant may induce fibrosis or may alter the collagen or elastin content, which subsequently results in a decrease in vaginal contractility. ${ }^{33}$ Despite the increase in stiffness of the $\mathrm{P} 4 \mathrm{HB}$ explants, the contractile function of the vagina implanted with $\mathrm{P} 4 \mathrm{HB}$ scaffold was higher than with PP mesh.

The implantation of $\mathrm{P} 4 \mathrm{HB}$ scaffold resulted in a higher number of inflammatory cells compared with PP mesh, which might be attributed to the higher areal density of P4HB scaffold compared with PP mesh ${ }^{4}$ or the continuing degradation of the P4HB scaffold. However, cellular infiltration of inflammatory cells within the P4HB scaffoldtissue interface was decreased over time and was followed by organised connective tissue at the later stage. Implant properties influence the inflammatory cell interactions at the implant-tissue interface and lead to altered foreign body responses upon implantation. ${ }^{34}$ Hjort et al. reported a moderate and decreased inflammatory response over time as a result of gradual implant degradation. ${ }^{23}$ If we look at the M2/M1 ratio, P4HB scaffolds were dominated by M2 macrophages compared with the PP mesh at 180 days post-implantation. The transition from the M1 to the M2 phenotype occurs with the initiation of the remodelling phase of wound healing, and enhanced tissue regeneration could be expected. ${ }^{35,36}$ In addition, myofibroblast differentiation, which plays a key role in the existence of fibrosis, ${ }^{37,38}$ was less pronounced in $\mathrm{P} 4 \mathrm{HB}$ at 180 days 
post-implantation compared with PP mesh. This finding also supports the result of a mechanically stronger tissue created by the effective remodelling process after $\mathrm{P} 4 \mathrm{HB}$ scaffold implantation.

We acknowledge some limitations of this study. We have used retrospective data for the PP mesh, as the design of the current study was identical to that of the previous study. This approach is in line with the aim of reducing the number of animals used in research. ${ }^{39}$ The duration of the study is not sufficient to demonstrate the tissue properties after the complete absorption of the $\mathrm{P} 4 \mathrm{HB}$ scaffold. To characterise the long-term performance of the $\mathrm{P} 4 \mathrm{HB}$ scaffold, a longer term follow-up is necessary.

On the other hand, this is the first preclinical study demonstrating the performance of the $\mathrm{P} 4 \mathrm{HB}$ scaffold as a transvaginal implant. We used a well-established animal model $^{4,16,33}$ for pelvic floor research. Additionally, the $\mathrm{P} 4 \mathrm{HB}$ scaffold was well characterised in our previous study, ${ }^{10}$ before transvaginal implantation.

\section{5 | CONCLUSION}

The P4HB scaffold exhibits good mechanical support to the vaginal tissue and results in a moderate host response in vivo without any visible implant-related complications. Although the data show a gradual load transfer from the P4HB scaffold to the vaginal tissue, the biomechanics of the tissue need to be further evaluated after complete degradation to determine whether the restored vaginal tissue strength and stiffness is self-sufficient to withstand the loads of daily life. Based on these encouraging results, we have started a 2-year followup study in sheep, prior to introducing the $\mathrm{P} 4 \mathrm{HB}$ scaffold clinically. The $\mathrm{P} 4 \mathrm{HB}$ scaffold may represent a unique fully absorbable alternative to permanent PP mesh for the surgical correction of POP in women.

\section{ACKNOWLEDGEMENT}

The authors express their gratitude to N.N. van der Wel and P.W.B. Larsen (Electron Microscopy Center Amsterdam and Department of Medical Biology, Amsterdam UMC, location AMC, Amsterdam, The Netherlands) for their assistance during SEM sample preparation and imaging.

\section{CONFLICT OF INTEREST}

CMD, ZG, LH, EV, MZ, EM and JPR declare that they have no competing interests. JD declares that he received a grant from Ethicon (J\&J) for an audit of women implanted with Alyte/Ultrapro for abdominal prolapse operations.

\section{AUTHOR CONTRIBUTIONS}

JPR, JD, CMD planned and developed the study. CMD and $\mathrm{LH}$ performed the implantations, and CMD, LH, EV and ZG performed the explantations and sample collection. ZG, CMD, EV, LH, MZ, EM performed data collection and analysis. ZG was the primary author of the manuscript, and all authors revised the manuscript and approved the final version.

\section{ETHICAL APPROVAL}

This study was conducted with the approval (LA1210191, approval date January 2016) of the Ethics Committee on Animal Experimentation of the Faculty of Medicine, $\mathrm{KU}$ Leuven and in adherence to experimental protocols (P057/2014//P 064/2013and P051/2016).

\section{DATA AVAILABILITY STATEMENT}

Data available on request from the authors.

\section{ORCID}

Chantal M. Diedrich (D) https://orcid. org/0000-0002-0579-3535

Zeliha Guler (D) https://orcid.org/0000-0001-7293-8151 Eva Vodegel (D) https://orcid.org/0000-0001-6897-9495 Jan Deprest (D) https://orcid.org/0000-0002-4920-945X

\section{REFERENCES}

1. Lakeman MM, van der Vaart CH, Laan E, Roovers JPW. The effect of prolapse surgery on vaginal sensibility. J Sex Med. 2011;8(4):1239-45.

2. Weber MA, Lakeman MM, Laan E, Roovers JPW. The effects of vaginal prolapse surgery using synthetic mesh on vaginal wall sensibility, vaginal vasocongestion, and sexual function: a prospective singlecenter study. J Sex Med. 2014;11(7):1848-55.

3. Liang R, Abramowitch S, Knight K, Palcsey S, Nolfi A, Feola A, et al. Vaginal degeneration following implantation of synthetic mesh with increased stiffness. BJOG. 2013;120(2):233-43.

4. Hympanova L, Rynkevic R, Roman S, Mori da Cunha M, Mazza E, Zundel $\mathrm{M}$, et al. Assessment of electrospun and ultra-lightweight polypropylene meshes in the sheep model for vaginal surgery. Eur Urol Focus. 2020;6(1):190-8.

5. Birch C, Fynes MM. The role of synthetic and biological prostheses in reconstructive pelvic floor surgery. Curr Opin Obstet Gynecol. 2002;14(5):527-35.

6. Barone WR, Moalli PA, Abramowitch SD. Textile properties of synthetic prolapse mesh in response to uniaxial loading. Am J Obstet Gynecol. 2016;215(3):326.e1-e9.

7. Kelly M, Macdougall K, Olabisi O, McGuire N. In vivo response to polypropylene following implantation in animal models: a review of biocompatibility. Int Urogynecol J. 2017;28(2):171-80.

8. Jones KA, Shepherd JP, Oliphant SS, Wang L, Bunker CH, Lowder JL. Trends in inpatient prolapse procedures in the United States, 19792006. Am J Obstet Gynecol. 2010;202(5):501.e1-e7.

9. Reinier M, Groep G. Final opinion on the use of meshes in urogynecological surgery. Brussels, Belgium: SCENIHR-European Commission; 2016.

10. Diedrich CM, Roovers JP, Smit TH, Guler Z. Fully absorbable poly4-hydroxybutyrate implants exhibit more favorable cell-matrix interactions than polypropylene. Mater Sci Eng C, Mater Biol Appl. 2021;120: 111702 .

11. O'Shaughnessy D, Grande D, El-Neemany D, Sajjan S, Pillalamarri N, Shalom D, et al. Evaluation of the histological and biomechanical properties of poly-4-hydroxybutyrate scaffold for pelvic organ prolapse, compared with polypropylene mesh in a rabbit model. Int Urogynecol J. 2021. http://dx.doi.org/10.1007/s00192-021-04851-6

12. Huisman GW, Skraly F, Martin DP, Peoples OP. Biological systems for manufacture of polyhydroxyalkanoate polymers containing 4-hydroxyacids. Google Patents; 2001.

13. Nelson T, Kaufman E, Kline J, Sokoloff L. The extraneural distribution of $\gamma$-hydroxybutyrate. J Neurochem. 1981;37(5):1345-8. 
14. Martin DP, Williams SF. Medical applications of poly-4hydroxybutyrate: a strong flexible absorbable biomaterial. Biochem Eng J. 2003;16(2):97-105.

15. Martin DP, Badhwar A, Shah DV, Rizk S, Eldridge SN, Gagne DH, et al. Characterization of poly-4-hydroxybutyrate mesh for hernia repair applications. J Surg Res. 2013;184(2):766-73.

16. Couri BM, Lenis AT, Borazjani A, Paraiso MFR, Damaser MS. Animal models of female pelvic organ prolapse: lessons learned. Exp Rev Obstet Gynecol. 2012;7(3):249-60.

17. Young N, Rosamilia A, Arkwright J, Lee J, Davies-Tuck M, Melendez $\mathrm{J}$, et al. Vaginal wall weakness in parous ewes: a potential preclinical model of pelvic organ prolapse. Int Urogynecol J. 2017;28(7):999-1004.

18. Ozog Y, Konstantinovic ML, Werbrouck E, De Ridder D, Edoardo M, Deprest J. Shrinkage and biomechanical evaluation of lightweight synthetics in a rabbit model for primary fascial repair. Int Urogynecol J. 2011;22(9):1099-108.

19. Hympanova L, Rynkevic R, Wach RA, Olejnik AK, Dankers PY, Arts $B$, et al. Experimental reconstruction of an abdominal wall defect with electrospun polycaprolactone-ureidopyrimidinone mesh conserves compliance yet may have insufficient strength. J Mech Behav Biomed Mater. 2018;88:431-41.

20. Deeken CR, Matthews BD. Characterization of the mechanical strength, resorption properties, and histologic characteristics of a fully absorbable material (Poly-4-hydroxybutyrate-PHASIX Mesh) in a porcine model of hernia repair. ISRN Surg. 2013;2013: 238067.

21. Roman S, Urbankova I, Callewaert G, Lesage F, Hillary C, Osman NI, et al. Evaluating alternative materials for the treatment of stress urinary incontinence and pelvic organ prolapse: a comparison of the in vivo response to meshes implanted in rabbits. J Urol. 2016;196(1):261-9.

22. Hympanova L, Mori da Cunha M, Rynkevic R, Zundel M, Gallego MR, Vange J, et al. Physiologic musculofascial compliance following reinforcement with electrospun polycaprolactone-ureidopyrimidinone mesh in a rat model. J Mech Behav Biom Mat. 2017;74:349-57.

23. Hjort H, Mathisen T, Alves A, Clermont G, Boutrand J. Three-year results from a preclinical implantation study of a long-term resorbable surgical mesh with time-dependent mechanical characteristics. Hernia. 2012;16(2):191-7.

24. Liang R, Knight K, Abramowitch S, Moalli PA. Exploring the basic science of prolapse meshes. Curr Opin Obstet Gynecol. 2016;28(5):413.

25. Nolfi AL, Brown BN, Liang R, Palcsey SL, Bonidie MJ, Abramowitch $\mathrm{SD}$, et al. Host response to synthetic mesh in women with mesh complications. Am J Obstet Gynecol. 2016;215(2):206.e1-e8.

26. Sand PK, Koduri S, Lobel RW, Winkler HA, Tomezsko J, Culligan PJ, et al. Prospective randomized trial of polyglactin 910 mesh to prevent recurrence of cystoceles and rectoceles. Am J Obstet Gynecol. 2001;184(7):1357-64.

27. De Tayrac R, Deffieux X, Gervaise A, Chauveaud-Lambling A, Fernandez $\mathrm{H}$. Long-term anatomical and functional assessment of trans-vaginal cystocele repair using a tension-free polypropylene mesh. Int Urogynecol J. 2006;17(5):483-8.

28. Ramanah R, Mairot J, Clement M-C, Parratte B, Maillet R, Riethmuller D. Evaluating the porcine dermis graft InteXen in three-compartment transvaginal pelvic organ prolapse repair. Int Urogynecol J. 2010;21(9):1151-6.

29. Armitage S, Seman EI, Keirse MJ. Use of surgisis for treatment of anterior and posterior vaginal prolapse. Obstet Gynecol Int. 2012;2012: 376251.

30. Williams SF, Martin DP, Moses AC. The history of GalaFLEX P4HB Scaffold. Aesthet Surg J. 2016;36(suppl 2):S33-42.

31. Utsunomia C, Ren Q, Zinn M. Poly(4-Hydroxybutyrate): current state and perspectives. Front Bioeng Biotechnol. 2020;8:257.

32. Feola A, Abramowitch S, Jallah Z, Stein S, Barone W, Palcsey S, et al. Deterioration in biomechanical properties of the vagina following implantation of a high-stiffness prolapse mesh. BJOG: an International Journal of Obstetrics \& Gynaecology. 2013;120(2):224-32.

33. Feola A, Endo M, Urbankova I, Vlacil J, Deprest T, Bettin S, et al. Host reaction to vaginally inserted collagen containing polypropylene implants in sheep. Am J Obstet Gynecol. 2015;212(4):474.e1-e8.

34. Cima LG. Polymer substrates for controlled biological interactions. J Cell Biochem. 1994;56(2):155-61.

35. Brown BN, Londono R, Tottey S, Zhang L, Kukla KA, Wolf MT, et al. Macrophage phenotype as a predictor of constructive remodeling following the implantation of biologically derived surgical mesh materials. Acta Biomater. 2012;8(3):978-87.

36. Hachim D, LoPresti ST, Yates CC, Brown BN. Shifts in macrophage phenotype at the biomaterial interface via IL-4 eluting coatings are associated with improved implant integration. Biomaterials. 2017;112:95-107.

37. Vashaghian M, Ruiz-Zapata AM, Kerkhof MH, Zandieh-Doulabi B, Werner A, Roovers JP, et al. Toward a new generation of pelvic floor implants with electrospun nanofibrous matrices: a feasibility study. Neurourol Urodyn. 2017;36(3):565-73.

38. Wynn TA, Ramalingam TR. Mechanisms of fibrosis: therapeutic translation for fibrotic disease. Nat Med. 2012;18(7):1028.

39. Burden N, Chapman K, Sewell F, Robinson V. Pioneering better science through the 3Rs: an introduction to the national centre for the replacement, refinement, and reduction of animals in research (NC3Rs). J Am Assoc Lab Anim Sci. 2015;54(2):198-208.

\section{SUPPORTING INFORMATION}

Additional supporting information may be found in the online version of the article at the publisher's website.

How to cite this article: Diedrich CM, Guler Z, Hympanova L, Vodegel E, Zündel M, Mazza E, et al. Evaluation of the short term host response and biomechanics of an absorbable poly-4-hydroxybutyrate scaffold in a sheep model following vaginal implantation. BJOG: Int J Obstet Gy. 2022;129:10391049. https://doi.org/10.1111/1471-0528.17040 